\title{
LITERATURA INFANTIL E ALFABETIZAÇÃO: UMA EXPERIÊNCIA PARA LER E ESCREVER
}

\author{
Daniela Segabinazi ${ }^{1}$ \\ Rosa Suzana Alves de Brito ${ }^{2}$
}

Resumo: Este artigo apresenta os resultados de pesquisa que procurou investigar e compreender as contribuições da literatura infantil no processo de aquisição da leitura e da escrita dos anos iniciais.Nesse sentido, relatamos a experiência decorrente de uma pesquisa qualitativa, "estudo de caso", realizada com uma turma de $1^{\circ}$ ano, em uma escola do município de Itapororoca, Paraíba. Inicialmente discutimos questões teóricas que versam sobre literatura infantil (REGO, 1995), alfabetização (FERREIRO; TEBEROSKI, 2011) e letramento literário (PAULINO; COSSON, 2009) e, posteriormente, descrevemos e mostramos os dados da análise resultantes da aplicação de um projeto de leitura desenvolvido durante seis meses na referida escola. Os resultados mostraram que as crianças chegam ao $1^{\circ}$ ano com muitas dificuldades de compreensão e de domínio das habilidades de leitura e escrita, assim como demonstram pouco contato com a literatura infantil. Contudo, a experiência realizada no estudo de caso evidenciou que a literatura infantil propicia ao pequeno leitor a participação e interação mais próxima à sua vida através da representação do mundo, estabelecendo elos entre o real e o imaginário, bem como aguça a fruição e a imaginação, sendo ideal para formação e constituição de um leitor fluente, crítico e reflexivo, contribuindo de forma única na aquisição da leitura e da escrita.

Palavras-chave: Educação. Literatura Infantil. Alfabetização. Letramento

\footnotetext{
${ }^{1}$ Doutora em Letras pela Universidade Federal da Paraíba (UFPB). Professora do Programa de Pós Graduação em -etras (PPGL/UFPB) e dos Cursos de Graduação em Letras (presencial e a distância) da UFPB. E-mail: Jani.segabinazi@gmail.com

${ }^{2}$ Graduada em Pedagogia e Geografia pela Universidade Federal da Paraíba, Especialista em Literatura e Ensino selo Instituto Federal de Educação, Ciência e Tecnologia do Rio Grande do Norte. Professora - Colégio Sigma e vicediretora da rede estadual de ensino da Paraíba. E-mail: suzana_britto@hotmail.com
} 


\title{
CHILDREN'S LITERATURE AND LITERACY: AN EXPERIENCE TO READING AND WRITING
}

\begin{abstract}
This paper shows the results of a research that aimed to investigate and understand the contributions of children's literature in the process of acquisition of reading and writing in the early years. In this sense, we report the experience originated from a qualitative research, "case study", carried out in a first-year classroom, in a school in Itapororoca, Paraíba. Initially, we discussed theoretical issues that deals on children's literature (REGO, 1995), literacy ((FERREIRO; TEBEROSKI, 2011) and literary literacy (PAULINO; COSSON, 2009), and, subsequently, we described and showed the data resulting from the application of a reading project developed during six months in such a school. The results showed that children achieve the first years with huge difficulty of reading and writing skills, as well as revealed the minimal contact with children's literature. However, the experience hold in the study case highlighted that children's literature provides to the young reader closer participation and interaction to his life through the representation of the world, establishing links between real and imaginary, as well as enhances enjoyment and imagination, ideal to the formation and the constitution of a fluent, critic and reflexive reader and contributing in an unique way in the acquisition of reading and writing.
\end{abstract}

Key Words: Education. Children's Literature. Literacy.

\section{LITERATURA INFANTIL Y ALFABETIZACIÓN: UNA EXPERIENCIA PARA LEER Y ESCRIBIR}

Resumen: Este artículo presenta los resultados de estudio que buscó investigar y comprender las contribuciones de la literatura infantil en el proceso de adquisición de la lectura y la escritura de los años iniciales. En ese sentido, relatamos la experiencia derivada de una investigación cualitativa, "estudio de caso", realizada con una clase de primer año, en una escuela del municipio de Itapororoca, Paraíba. En primer lugar discutimos cuestiones teóricas que versan sobre literatura infantil (REGO, 1995), alfabetización (FERREIRO, TEBEROSKI, 2011) y alfabetización literaria (PAULINO, COSSON, 2009) y, posteriormente, describimos y mostramos los datos del análisis resultantes de la aplicación de un proyecto de lectura desarrollado durante seis meses en dicha escuela. Los resultados mostraron que los niños llegan al primer año con muchas dificultades de comprensión y dominio de las habilidades de lectura y escritura, así como demuestran poco contacto con la literatura infantil. Sin embargo, la experiencia realizada en el estudio de caso evidenció que la literatura infantil propicia al pequeño lector la participación e interacción más cercana a su vida a través de la representación del mundo, estableciendo eslabones entre lo real y lo imaginario, así como aguza la fruición y la imaginación, siendo ideal para la formación y constitución de un lector fluido, crítico y reflexivo, y contribuyendo de forma única en la adquisición de la lectura y la escritura.

Palabras clave: Educación. Literatura infantil. Alfabetización. Alfabetización literaria. 
É à literatura, como linguagem e como instituição, que se confiam os diferentes imaginários, as diferentes sensibilidades, valores e comportamentos através dos quais uma sociedade expressa e discute, simbolicamente, seus impasses, seus desejos, suas utopias. Por isso a literatura é importante no currículo escolar: o cidadão, para exercer, plenamente sua cidadania, precisa apossar-se da linguagem literária, alfabetizar-se nela, tornar-se seu usuário competente, mesmo que nunca vá escrever um livro: mas porque precisa ler muitos. (LAJOLO, 2008).

Ao abrirmos nossas discussões em torno da alfabetização e da literatura, adiantamos nossa visão acerca da literatura na escola como peça fundamental na constituição de um leitor, abrindo caminhos para o exercício da compreensão e ponto de partida para a leitura de outros textos, variando os gêneros e temas de leitura. Neste caso, a literatura infantil oferece ao leitor a diversidade cultural, social, ética e estética que, possivelmente, ainda não conhece, ampliando seu horizonte no encontro com o universo da ficção, da fantasia, do imaginário e de sua própria identidade.

O papel da escola, então, torna-se imprescindivel, especialmente, na figura do professor que precisa agir como agente de mediação na formação de leitores, pois de acordo com Peruzzo (2011, p. 96) “[...] a leitura deve ser vista como um instrumento que leva a transformação da cultura alienante em instrumento à serviço da cidadania”. Sobretudo, se a escola auxiliar o trabalho pedagógico do professor, ao possibilitar a organização de um espaço/ambiente ou momentos em que a criança possa manusear livros infantis e ter acesso a diferentes gêneros literários.

Desse modo, o contato da criança com o livro deve começar desde muito cedo, não sendo necessário que esse contato aconteça apenas quando a criança entra no sistema educacional ou quando 'já sabe ler'. Por isso, trataremos da literatura infantil no processo de letramento e alfabetização sob uma perspectiva teórico-metodológica planejada, destacando uma experiência com projeto de leitura de literatura infantil ${ }^{3}$, realizado com uma turma de

\footnotetext{
${ }^{3}$ Para este trabalho optamos por apresentar um recorte do projeto de leitura, enfatizando as propostas metodológicas que envolveram a leitura de obras literárias infantis e dando
} 
primeiro ano, dos anos iniciais, em uma escola do Estado da Paraíba, o que torna as discussões mais consistentes quanto a prática da leitura e da escrita na alfabetização, quando já vividas e relatadas como resultados de uma ação que deu certo.

\section{Alfabetização e letramento literário}

A alfabetização passou por diferentes estudos durante sua trajetória histórica, no entanto, o conceito de alfabetização se identificou com o ensinoaprendizado da leitura e da escrita, no sentido de codificar os sons da fala e decodificar os sinais gráficos. Todavia, sabemos que, "Ler e escrever são processos complexos - o segundo ainda mais complexo que o primeiro -, que exigem conhecimentos de natureza sintática, semântica e pragmático-cultural, que o leitor vai adquirindo à medida que amplia o seu léxico ortográfico [...].” (BORTONI, 2006, p. 204).

Assim, na busca da compreensão do método ou métodos, foi possivel perceber que na alfabetização predominam dois métodos bem distintos: o sintético e o analítico. Os métodos sintéticos partem de elementos mínimos, primeiro às letras ou fonemas e depois para maiores como sílabas/palavras/frases; já os métodos analíticos entendem a leitura como um ato global, que deve iniciar com unidades significativas para a criança, partindo do todo até chegar a um elemento menor.

Apesar disso, a partir do início da década de 1980, o conceito de alfabetização foi ampliado, principalmente em razão dos estudos e contribuições de Ferreiro e Teberosky (2011) que desenvolveram trabalhos na busca da compreensão sobre a aquisição da linguagem oral e escrita da criança, mudando também os métodos de ensino aprendizagem na alfabetização.

Para Ferreiro e Teberosky (2011), durante o processo de alfabetização é imprescindivel que se leve em consideração as concepções da criança a respeito do sistema de escrita, pois a criança não se depara com a linguagem escrita no

alguns exemplos dos resultados para comprovação de como é possivel ler e escrever na escola a partir do letramento literário. 
primeiro dia de escola. Quando a criança chega à escola (às vezes mais, às vezes menos) já teve contato com a escrita e já consegue dominar um vocabulário específico da comunidade na qual está inserida. Sendo assim, o professor deve levar em consideração o conhecimento prévio dos alunos uma vez que, "[...] a criança que se inicia na alfabetização já é um falante capaz de entender e falar a língua portuguesa com desembaraço e precisão nas circunstâncias de sua vida em que precisa usar a linguagem [...]." (CAGLIARI, 1992, p. 29).

Do ponto de vista construtivista, a escrita infantil segue uma linha evolutiva, em que há três periodos distintos, dos quais cabem múltiplas subdivisões. No primeiro período, a criança consegue realizar duas diferenças básicas que subsidiarão as construções posteriores: as marcas gráficas figurativas e as não figurativas, a distinção entre desenhar e escrever (ao desenhar está no domínio do icônico e ao escrever está fora do icônico).

O segundo período é caracterizado pela diferenciação. No primeiro momento a criança começa a notar que além dos desenhos existem as letras e os números. No início usam os números e as letras indistintamente, mas, posteriormente, percebem que são necessários determinados signos, que não são os desenhos, nem os números para escrever. No passo seguinte, as crianças exploram critérios que lhes permitem, algumas vezes, variações sobre o eixo quantitativo e qualitativo.

[...] eixo quantitativo (variar a quantidade de letras de uma escrita para outra, para obter escritas diferentes), e às vezes, sobre o eixo qualitativo (variar o repertório de letras que se utiliza de uma escrita para outra; variar a posição das mesmas letras sem modificar a quantidade). A coordenação dos dois modos de diferenciação (quantitativos e qualitativos) é tão dificil aqui como em qualquer outro domínio da atividade cognitiva. (FERREIRO; TEBEROSKY, 2011, p. 23).

Nos dois primeiros períodos, a criança acredita que a forma de escrever é regida por princípios ideográficos, ela ainda não percebe semelhanças ou diferenças entre o escrito e os significantes sonoro. Será a atenção às propriedades sonoras que permitirá a criança entrar no período de fonetização da escrita. 
De acordo com Ferreiro e Teberosky (2011, p. 27):

A criança começa por descobrir que as partes da escrita (suas letras) podem corresponder a outras tantas partes da palavra escrita (suas silabas). Sobre o eixo quantitativo, isto se exprime na descoberta de que a quantidade de letras com que vai se escrever uma palavra pode ter correspondência com a quantidade de partes que se reconhece na emissão oral. Essas 'partes' da palavra são inicialmente as suas sílabas. Inicia-se assim o período silábico, que evolui até chegar a uma exigência rigorosa: uma sílaba por letra, sem omitir sílabas e sem repetir letras.

O período silábico é muito importante e imprescindível para o desenvolvimento da criança, pois nele há situações de incongruências, que permite a criança avançar cada vez mais no processo de aquisição da escrita, como por exemplo: a incompatibilidade entre a quantidade mínima de letras que uma escrita deve possuir e as partes sonoras semelhantes entre as palavras, essas contradições se tornam conflitos que progressivamente vão desestabilizando a hipótese silábica. Ao se desestabilizar a hipótese silábica inicia-se então o período silábico-alfabético, que é a transição entre o período silábico e o período alfabético. Ferreiro e Teberosky (2011, p. 29) enfatizam isso ao afirmar que "O período silábico-alfabético marca a transição entre os esquemas prévios em via de serem abandonados e os esquemas futuros em vias de serem construídos."

E, por último, o período alfabético "Quando a criança descobre que a sílaba não pode ser considerada como uma unidade, mas que ela é por sua vez, reanalisável em elementos menores." (FERREIRO; TEBEROSKY, 2011, p. 29). Neste período, a criança já consegue escrever todas as letras de uma palavra, no entanto, aparecem novos problemas de escrita como, por exemplo, os problemas ortográficos.

Diante dos resultados destes estudos, a alfabetização se caracteriza “[...] como um processo ativo por meio do qual a criança, desde seus primeiros contatos com a escrita, construiria e reconstruiria hipóteses sobre a natureza e o funcionamento da lingua escrita, compreendida como um sistema de representação." (BRASIL, 2008, p. 10). Portanto, é importante que haja algumas mudanças nas práticas pedagógicas durante o processo de 
alfabetização, para que desta maneira seja possivel se obter resultados satisfatórios.

Outro conceito importante e associado a nova forma de compreender a alfabetização está ligado ao termo 'Letramento', com conceitos distintos, mas correlatos. Vimos que, historicamente, o conceito de alfabetizar passou a identificar-se com o ensino-aprendizado da 'tecnologia da escrita', assim até os anos 1980, a alfabetização limitava-se apenas a ler e escrever palavras.

[...] primeiro, era preciso aprender a ler, para só depois ler. Embora pareça uma afirmação contraditória, acreditava-se que a criança não podia ler antes que soubesse ler: não podia "ler de verdade" antes que fosse capaz de "decodificar" a lingua escrita, aprendida em "textos" construídos não para ler, mas para ensinar a ler. (SOARES, 2010, p.14).

Nestes textos as palavras eram intencionalmente selecionadas para decomposição em sílabas e fonemas. A criança não tinha acesso a livros, a gibis ou a qualquer tipo de material escrito que não fossem os selecionados, sem antes passar pelo processo de codificação e decodificação das palavras. Os textos lidos pelo aluno alfabetizado, neste contexto educacional de alfabetização, serviam apenas para que o aluno fizesse uma leitura mecânica e memorizada e, sob este aspecto, a literatura infantil estava fora desse processo.

Com o advento de novos estudos e pesquisas, houve a incorporação de concepções sobre o letramento, distinguindo-o da alfabetização e ao mesmo tempo contribuindo para esta. A partir de um conceito simples, podemos dizer que letramento é colocar em prática as habilidades de um leitor que consegue refletir e pensar diante de situações problemas postos pela sociedade.

Com essa nova concepção, a linguagem passa a ser vista como um lugar de interação humana, na qual os usuários são sujeitos que ocupam lugares sociais, de acordo com suas formações ideológicas, conhecimento de mundo e crenças, e a língua tornase instrumento de interação social, que não existe por si mesma, mas em virtude do uso para fim de interação entre os seres humanos, não sendo mais um objeto descontextualizado que não apresenta relação entre os seus constituintes e os seus significados, ou seja, entre a língua e o seu uso. (VIEIRA, 2011, p.6). 
Assim, o letramento amplia o conceito de alfabetização, atribuindo significados ao uso da língua e da construção da escrita nas ações cotidianas da vida do sujeito, pois só alfabetizar já não basta. A importância do letramento adquire outros contornos, passando a fazer parte também do ensino da literatura, traduzindo-se, atualmente, em letramento literário quando o objetivo é formar leitores competentes na leitura do texto literário.

Paulino e Cosson (2009, p. 67) definem letramento literário como "[...] o processo de apropriação da literatura como construção literária dos sentidos." Para os autores, o letramento literário é um processo que acontece de forma contínua e permanente e que se intercala entre a escola e o meio social. Os autores afirmam, ainda, que:

[...] considerar o letramento literário um processo significa tomálo como um estado permanente de transformação, uma ação continuada, e não uma habilidade que se adquire como aprender a andar de bicicleta ou um conhecimento facilmente mensurável como a tabuada de cinco. Também deve ficar claro que o letramento literário não começa nem termina na escola, mas é uma aprendizagem que nos acompanha por toda a vida e que se renova a cada leitura de uma obra significativa. Depois, trata-se de apropriação, isto é, um ato de tornar próprio, de incorporar e com isso transformar aquilo que se recebe, no caso, a literatura. [...] Por fim, trata-se da apropriação da literatura não apenas como um conjunto de textos, consagrados ou não, mas também como um repertório cultural que proporciona uma forma singular - literária - de construção de sentidos. (PAULINO; COSSON, 2009, p. 67-68).

Sob este enfoque, vale salientar que o letramento literário deve ser trabalhado no interior da escola a fim de que a literatura seja uma experiência vivida pelos alunos, porém a literatura não deve deixar de possuir em sua essência a humanização e o prazer da leitura, bem como

Não há nada de errado em utilizar textos de literatura quando tratamos do estudo da língua portuguesa; seria incoerente pensar assim, quando reconhecemos na literatura uma especial manifestação da língua. A ressalva está na tendência a sua pura escolarização. Dar utilidade para o texto literário antes de permitir o encontro do estudante com a arte, é sabotar o leitor e desconsiderar o papel humanizador que a escola precisa ter. (LOIS, 2010, p. 35).

Ao abordar a questão da utilização dos textos literários, Lois (2010) deixa claro que eles devem ser utilizados na escola, sendo inevitável sua 
escolarização; assim a escolarização da literatura deve permitir o diálogo com a subjetividade, o acesso ao saber literário no ambiente escolar, estimulando o leitor à apropriação de diferentes pontos de vista num ambiente de letramento literário, pois aí reside o início à formação do leitor dentro de uma comunidade de leitores, que se expressa, dialoga, expõe suas ideias, compreende o que lê, faz críticas aos textos lidos e que é conduzido mais eficazmente às práticas de leituras em um contexto social.

Portanto, no processo de aquisição da leitura e da escrita a literatura contribui de forma impar, uma vez que o texto literário promove muitas perguntas e diversos caminhos que podem ser trilhados a partir da interpretação de cada leitor, concomitante com as perguntas sobre a escrita. Entretanto, para que o letramento literário se efetive na escola, será necessário que o aluno seja envolvido por práticas pedagógicas que o estimulem a se tornar um leitor fluente, crítico e reflexivo, isto é, competente. Ao professor cabe criar situações para que haja o encontro do aluno com a literatura, pois ele é o principal mediador no processo de formação desse leitor e “[...] cada novo leitor, formado consciente, sinaliza para o desenvolvimento de mais um cidadão." (LOIS, 2010, p. 65).

\section{Ler e escrever literatura na escola: resultados que dão certo!}

O estudo que passamos a relatar consistiu em verificar e analisar como a literatura infantil contribui no processo de aquisição da leitura e da escrita no primeiro ano do ciclo da alfabetização. Para atingir os objetivos, foi aplicado um projeto de leitura de obras literárias, a partir do diagnóstico, em uma turma com 15 alunos do $1^{\circ}$ ano, do Ensino Fundamental, na cidade de Itapororoca, no Estado da Paraíba. A utilização da metodologia de projetos de trabalho foi escolhida por estabelecer a relação entre o ensino e aprendizagem dos alunos de maneira dinâmica, lúdica, reflexiva e sistematizada. Segundo Barbosa (2008, p. 53), “Todo projeto é processo criativo dos alunos e professores, possibilitando o estabelecimento de ricas relações entre o ensino e aprendizagem, que certamente não passa por superposição de atividades.”. 
Desta forma, pode-se compreender que o trabalho com projeto permite que o docente trabalhe interdisciplinarmente, no entanto, é imprescindivel afirmar que o projeto quando direcionado ao trabalho literário torna-se, ainda mais importante, pois o projeto de leitura com livros de literatura infantil proporciona uma diversidade de situações favoráveis à leitura e ao registro de experiências através da escrita, ou seja, a vivência da escrita como prática, tornando-se, assim, um projeto de letramento.

Durante a execução do projeto foi possivel acompanhar, durante seis meses, o processo de ensino-aprendizagem e a transformação cognitiva e afetiva pelo qual as crianças passaram; por isso, paralelamente foram feitas observações e registros após a realização de cada atividade do projeto e, assim, obtidas informações indispensáveis para a análise e compreensão do processo de alfabetização e do letramento literário, tomando como base teórica as concepções delineadas anteriormente neste artigo.

Inicialmente, a atividade diagnóstica objetivou a coleta de dados para a avaliação do desenvolvimento inicial de leitura e escrita das crianças ao chegarem ao primeiro ano, do ensino fundamental, bem como nos proporcionou, a partir dessa verificação, a feitura de um projeto de literatura infantil que atendesse a necessidade da turma. A atividade consistiu na leitura de imagem da história $O$ Telefone (Fig. 01), presente no livro A bruxinha atrapalhada, de Furnari (1982). 
Figura 1 - História $O$ Telefone, do livro A bruxinha atrapalhada, de Furnari.
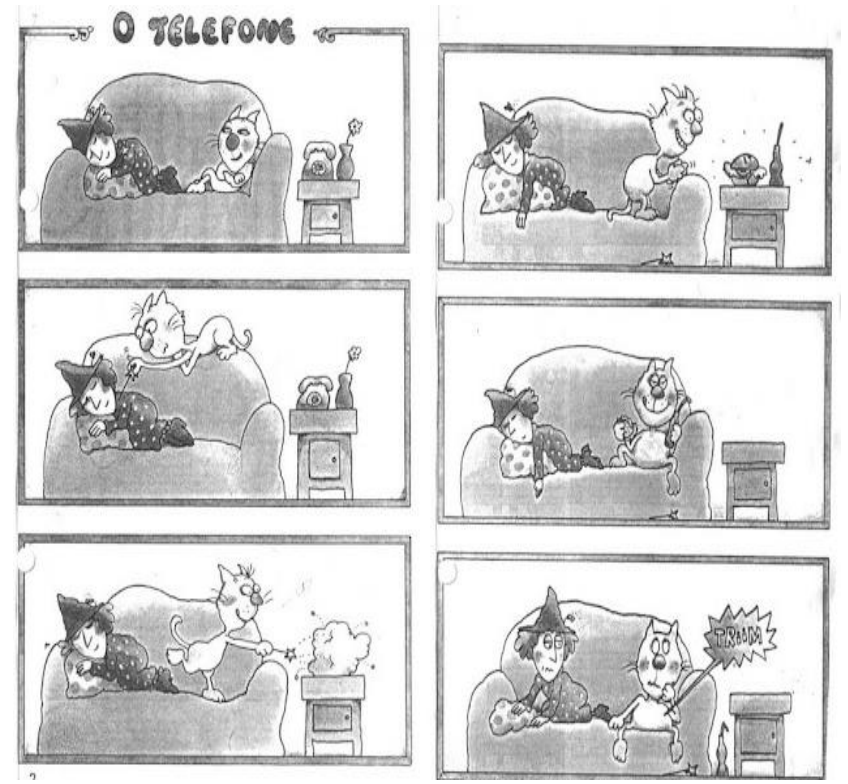

Fonte: Reproduzido pelas autoras.

A história foi apresentada, individualmente, e, em seguida, foi solicitado a cada criança que contasse o que estava vendo e, posteriormente, escrevesse a narrativa a partir das imagens. Ao propor esta atividade, entendemos que a sequência de imagens permite aprender as articulações da escrita que são necessárias para a demonstração do desenvolvimento das ações, uma vez que a criança interpreta as imagens sequenciadas e, posteriormente, consegue ordená-las, o que vai configurando noções de tempo, espaço, sequência narrativa, coesão e coerência na organização de textos, sejam eles orais ou escritos. Vejamos, no quadro 1 , como algumas crianças $^{4}$ fizeram a leitura e como escreveram sua história.

4 Para manter a identidade das crianças foram utilizadas as denominações A1, A2, A3 e, assim sucessivamente, até A15. 
Quadro 1- Atividade avaliativa diagnóstica de leitura e escrita

\begin{tabular}{|c|c|c|}
\hline Aluno & Avaliação diagnóstica & Leitura/Escrita \\
\hline A 1 & $\begin{array}{l}\text { Conseguiu contar a história } \\
\text { em uma sequência lógica e } \\
\text { identificou os personagens e } \\
\text { os objetos das imagens. }\end{array}$ & $\begin{array}{l}\text { Leu: A bruxa estava dormindo } \\
\text { comendo sanduiche tomando o } \\
\text { suco encheu a barriga. } \\
\text { Escreveu: } \\
\text { buSatavaddoqumnuSacsitaucu } \\
\text { quicuaRaRia }\end{array}$ \\
\hline A2 & $\begin{array}{l}\text { Não conseguiu contar a } \\
\text { história, disse apenas o nome } \\
\text { de alguns objetos, por } \\
\text { exemplo: telefone, flor, sofá e } \\
\text { etc. }\end{array}$ & $\begin{array}{l}\text { Leu: gato } \\
\text { aitber- leu: moço dormindo } \\
\text { Escreveu: bit- leu: telefone } \\
\text { Uuoa }\end{array}$ \\
\hline A5 & $\begin{array}{l}\text { Conseguiu contar a história } \\
\text { em uma sequência lógica e } \\
\text { identificou os personagens e } \\
\text { objetos das imagens. }\end{array}$ & $\begin{array}{l}\text { Leu: estava dormindo com o } \\
\text { gato. O gato fez desaparece o } \\
\text { telefone e comeu tudo, ela se } \\
\text { acordou e ele se fez de santinho } \\
\text { para ela não brigar com ele. } \\
\text { Escreveu: lauiuaouauoa }\end{array}$ \\
\hline A12 & $\begin{array}{l}\text { Não conseguiu contar a } \\
\text { história em uma sequência } \\
\text { lógica, disse apenas frases } \\
\text { soltas para cada imagem e } \\
\text { identificou os personagens e } \\
\text { objetos das imagens. }\end{array}$ & $\begin{array}{l}\text { Leu: O gato e a bruxa. } \\
\text { O gato acordado. } \\
\text { Escreveu: Gato bruja u Gato } \\
\text { cecodado. }\end{array}$ \\
\hline A 15 & $\begin{array}{l}\text { Não conseguiu contar a } \\
\text { história em uma sequência } \\
\text { lógica, disse frases soltas para } \\
\text { cada imagem e só identificou } \\
\text { um dos personagens. }\end{array}$ & $\begin{array}{l}\text { Leu: Ele dormindo mais a } \\
\text { mulher. } \\
\text { O jarro caindo da mulher e ele foi } \\
\text { pegar ele estava com fome. } \\
\text { Escreveu: } \\
\text { urudubuabucepeuSaudaubuceb } \\
\text { oabucabudeacibalaHa. }\end{array}$ \\
\hline
\end{tabular}

Fonte: Brito (2013).

Em relação à leitura que os alunos fizeram das imagens, foi possivel perceber que $87 \%$ das crianças não conseguiram narrar à história em uma sequência lógica, ordenada conforme as cenas, disseram apenas frases soltas e, em alguns casos, descontextualizadas em relação às imagens. Podemos, talvez, atribuir este fato ao método tradicional de ensino pelo qual as crianças passam na educação infantil, em que a língua escrita é apresentada inicialmente à criança como um código descontextualizado, em que as convenções da escrita são, primeiramente, dominadas pela criança para, posteriormente, conhecer e reconhecer seu valor de uso em práticas sociais de letramento, e, também porque não possuem familiaridade com a literatura infantil e esse tipo de atividade. Nesse sentido, Rego (1995, p.15) afirma que: 
As crianças despendem boa parte do tempo nas classes de pré-escolar modelando massas, recortando papéis, ligando pontos, reconhecendo semelhanças e diferenças entre figuras, discriminado sons, trabalhando, enfim, os movimentos das mãos e as habilidades discriminatórias consideradas essenciais no processo de alfabetização.

Assim, entendemos também que a educação infantil que estas crianças frequentaram está basicamente voltada para a preparação da alfabetização, que se organizava em torno das seguintes aptidões: coordenação motora, descriminação perceptual e linguagem oral etc. desconhecendo o universo literário, pois estas crianças não tinham contato com o texto literário.

No que diz respeito ao que as crianças escreveram, podemos notar que estão em diferentes niveis de escrita e que há também reflexos do método de ensino sintético, totalmente fragmentado, em que as crianças só têm contato com textos reconhecidos como 'papai viu a pipa', 'A babá e boa', que tem como finalidade apenas o êxito no processo de decodificação, evitando as correspondências grafônicas que ainda não foram ensinadas às crianças (REGO, 1995).

Após a avaliação diagnóstica e com o resultado da coleta destes dados foi iniciada a execução do projeto de leitura e escrita a partir da leitura integral de obras da literatura infantil, com a preocupação em manter o letramento literário e a alfabetização em consonância. A seguir, passamos a relatar e mostrar os resultados desse projeto, uma experiência que nos forneceu resultados positivos no processo de alfabetização das crianças, consoante as discussões teórico-metodológicas aqui expostas.

\subsection{O desenrolar de um projeto pedagógico na sala de aula}

Para melhor leitura e compreensão do desenvolvimento e dos resultados obtidos no projeto, vamos descrever os procedimentos didáticos realizados com cada obra literária (objetivo e metodologia), e disponibilizar um recorte dos resultados a partir de exemplos de como algumas crianças conseguiram fazer a atividade. Vamos destacar as análises e avaliações a respeito do processo de aquisição da leitura e da escrita das crianças envolvidas no projeto, no intuito de mostrar como um trabalho bem planejado e com bases teóricas bem 
compreendidas podem dar certo, isto é, podem oferecer excelentes resultados na alfabetização e para o letramento literário. Dessa forma, passamos a descrever todas as atividades e leituras das obras literárias do projeto.

$1^{\circ}$ Atividade - O peru de Peruca - Os objetivos foram estimular a leitura e a compreensão do texto e trabalhar com a leitura de imagens. Metodologia utilizada: No início da aula foi feito um círculo e mostramos o livro O Peru de Peruca (Fig.02) para as crianças.

Figura 2 - Capa do livro O peru de peruca, Junqueira (2004).

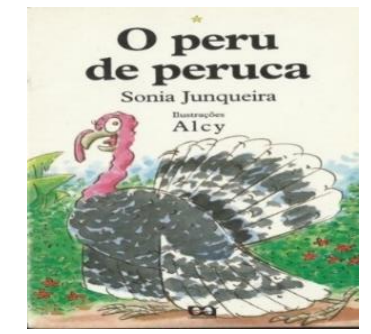

Fonte: Reproduzido pelas autoras

Em seguida, questionamos a respeito da obra: o que vocês acham que vai se falar no livro? Vocês já viram esse animal que está na capa deste livro? etc. Após a atividade de motivação, começamos a leitura do livro e, na sequência, fizemos uma roda de conversa para saber o que as crianças acharam do livro (durante a conversa as crianças manusearam o livro, individualmente, para melhor observar as ilustrações).

Depois da roda de conversa pedimos para que os alunos (individualmente) escrevessem o nome dos personagens do livro, formando uma lista de palavras. Quando todos escreveram, solicitamos que cada criança falasse como escreveu o nome dos personagens e colocamos da mesma maneira no quadro. Após, fizemos a correção de forma coletiva, fazendo assim com que o aluno refletisse sobre como escreveu e a maneira correta de escrever. Ressaltamos, no entanto, que as crianças não lembraram do nome de todos os personagens do livro, por isso foi necessário ler o livro duas vezes. Os resultados e as análises de alguns alunos se encontram apresentados nos quadros que seguem. O quadro 2 corresponde ao registro escrito dos alunos. 
Quadro 2 - Resultados da $1^{\circ}$ Atividade

\begin{tabular}{|l|l|c|c|c|}
\hline \multicolumn{5}{|c|}{ Escrita da lista dos personagens da história } \\
\hline Aluno & & Personagens / Escrita dos alunos \\
\hline & Ari & Mara & Xerife & Vera \\
\hline A1 & Ai & AA & Eife & Ea \\
\hline A2 & I & A & Ie & AA \\
\hline A10 & Ari & Maa & Xeie & Vea \\
\hline A12 & Ai & AA & Eie & Vea \\
\hline A13 & Mha & Mic & Miceh & A \\
\hline
\end{tabular}

Fonte: Brito (2013).

O quadro 3, que apresentamos abaixo, corresponde a análise avaliativa do desenvolvimento da escrita desses alunos.

Quadro 3 - Análise da $1^{\circ}$ Atividade

\begin{tabular}{|c|c|c|c|c|c|c|c|}
\hline \multicolumn{8}{|c|}{ Escrita da lista dos personagens da história } \\
\hline & \multicolumn{4}{|c|}{ Niveis de Escrita } & \multirow{2}{*}{$\begin{array}{l}\text { Disposição } \\
\text { gráfica da } \\
\text { lista }\end{array}$} & \multirow{2}{*}{$\begin{array}{l}\text { Lembrança } \\
\text { lista } \\
\text { completa de } \\
\text { nomes }\end{array}$} & \multirow{2}{*}{$\begin{array}{l}\text { Confusões } \\
\text { ou } \\
\text { imprecisões } \\
\text { sobre os } \\
\text { nomes }\end{array}$} \\
\hline Aluno & $\begin{array}{l}\text { Pré- } \\
\text { Silábico }\end{array}$ & Silábico & $\begin{array}{l}\text { Silábico/ } \\
\text { Alfabético }\end{array}$ & Alfabético & & & \\
\hline A1 & & $\mathbf{x}$ & & & & & $\mathbf{X}$ \\
\hline A2 & $\mathbf{X}$ & & & & & & $\mathbf{x}$ \\
\hline A10 & & $\mathbf{x}$ & & & & & $\mathbf{x}$ \\
\hline A12 & & $\mathbf{X}$ & & & & & $\mathbf{X}$ \\
\hline A13 & $\mathbf{x}$ & & & & & & $\mathbf{x}$ \\
\hline
\end{tabular}

Fonte: Brito (2013).

Após a atividade foi possivel perceber que 53\% das crianças estão no nível de escrita pré-silábico. No entanto, é importante salientar que estas crianças não utilizam mais rabiscos ou desenhos para representar a escrita da palavra, portanto há um considerável avanço, pois elas compreendem que a palavra escrita representa o nome da coisa a que se refere e não a coisa diretamente. Ainda, neste nível, mesmo após tomar consciência de que se escreve com letras, os alunos grafam um número de letras indiscriminadamente, sem antecipar quantos e quais caracteres precisará usar para registrar palavras, como vimos na escrita dos nomes dos personagens do livro $\mathbf{O}$ peru de peruca. Grossi (1985, p.15) sintetiza o nivel pré-silábico como:

[...] caminhada em dois grandes trilhos paralelos: um deles é o reconhecimento de que letras desempenham um papel na escrita e outro na compreensão ampla da vinculação do discurso oral com o texto escrito. A didática do nível pré-silábico visa, 
entre outras coisas, a que a criança distinga imagem de texto, letras de números, e que estabeleça macro- vinculações do que se pensa com o que se escreve, superando critérios do pensamento intuitivo.

Nesse sentido, a criança avança progressivamente e caminha para o nivel silábico e, neste momento, há um conflito entre a hipótese silábica e a quantidade mínima de letras exigida para que a escrita possa ser lida. Para Santamaria, Leitão e Assencio-Ferreira (2004, p. 237), o nível silábico:

[...] consiste na organização de uma hipótese central: a criança compreende que para ler "coisas" diferentes, deve escrevê-las de formas diferentes; há uma maior preocupação em fazer correspondência com o número de letras e o número de silabas. Podemos evidenciar nesta fase os grafismos mais definidos, mais próximos ao das letras. Nesta etapa a criança cria uma representação silábica contendo ou não valor sonoro convencional, fonetização da escrita.

Nesta fase surge o reconhecimento entre a fala e a escrita, sendo assim observamos que $47 \%$ das crianças já estão no nivel silábico, pois começaram a grafar uma letra para cada sílaba; por exemplo, a $\mathbf{A 1 2}$ escreve a palavra Xerife da seguinte maneira: eie, apresentando a escrita silábica, isto é, a unidade de som que se percebe é a sílaba e cada sílaba é representada por uma letra ou um grafema.

$2^{a}$ Atividade - música $O$ peru - Interligada a leitura do livro o peru de peruca, o objetivo foi desenvolver a criatividade dos alunos. Metodologia utilizada: Iniciamos colocando a música O peru de Vinicius de Morais, para que os alunos realizassem a audição e a apreciação musical, em seguida confeccionamos perucas junto com as crianças. Durante esta atividade foi possivel trabalhar os aspectos lúdicos proporcionados pela literatura e sua interface com a música de Vinicius de Morais, estimulando a leitura com prazer, o prazer da leitura e o prazer da arte.

Os resultados obtidos foram excelentes, pois as crianças se divertiram muito ao ouvir a música de Vinicius de Morais e ao confeccionar as perucas, portanto, o texto literário lido na atividade anterior atrelado a essa atividade conseguiu atingir uma de suas intenções que é produzir prazer e envolvimento afetivo com a literatura. 
$3^{\circ}$ atividade - Chá das dez - Os objetivos específicos foram incentivar a leitura e trabalhar a expressão oral. Metodologia utilizada: Organizamos a sala para torná-la um ambiente acolhedor, colocando vários livros para que os alunos escolhessem e manuseassem livremente. Depois pedimos para que os alunos escolhessem um livro para a contação da história e o livro foi Chá das Dez, de Celso Sisto (2010).

Após a leitura, para a tarefa de casa, solicitamos que as crianças recontassem a história ouvida na sala de aula para seus pais e, com ajuda deles, escrevessem a história novamente, na perspectiva de uma reconstrução da narração, que para Curto, Morillo e Teixidó (2000, p. 128) significa:

A reconstrução não é somente um resumo do argumento, do conteúdo ou da narração. Na reconstrução interessa, além da fidelidade ao argumento, a utilização dos elementos lingüisticos próprios do conto e da narração. [...]

Ao recompor um texto, não se limitam a imitar: trazem suas próprias ideias acerca de como se constrói o texto e sobre o conteúdo. Dai surge o debate e a aprendizagem compartilhada: sobre a estrutura do conto ou texto, o esquema narrativo, a lógica do texto, a inserção de frases ou elementos característicos.

Desta forma, ao recontar e reconstruir uma história, a criança se apropria de elementos fundamentais que estão presentes em uma narrativa, assimilando características do texto escrito e ampliando o seu conhecimento. Eis o resultado da tarefa:

Quadro 4 - Resultados da $3^{\text {a }}$ atividade

\begin{tabular}{|c|l|}
\hline \multicolumn{2}{|c|}{ Recontação do livro Chá das dez } \\
\hline Aluno & \multicolumn{1}{|c|}{ Resultado } \\
\hline A1 & $\begin{array}{l}\text { Não conseguiu recontar a história, lembrou apenas da vovó e da } \\
\text { viagem. }\end{array}$ \\
\hline A2 & Conseguiu recontar uma pequena parte da narrativa do livro. \\
\hline A3 & Não conseguiu recontar a história. \\
\hline A12 & Criou outra história utilizando os personagens do livro. \\
\hline A15 & $\begin{array}{l}\text { Conseguiu recontar a história (lembrou de muitos detalhes } \\
\text { presentes na narrativa). }\end{array}$ \\
\hline
\end{tabular}

Fonte: Brito (2013). 
$\mathrm{Na}$ análise, quando afirmamos que a criança conseguiu recontar a história não é que ela fez uma narração contendo todos os detalhes presentes no livro, mas sim que logrou compreender e narrar uma quantidade considerável de informações que estavam presentes no livro. Assim, para analisar esta atividade levamos em consideração os seguintes aspectos que constam no quadro a seguir:

Quadro 5 - Análise da $3^{\circ}$ atividade

\begin{tabular}{|l|c|c|c|c|c|c|c|}
\hline \multicolumn{7}{|c|}{ Recontação do livro “Chá das dez" } \\
\hline Aluno & $\begin{array}{c}\text { Compreensão } \\
\text { da história }\end{array}$ & $\begin{array}{c}\text { Ordem } \\
\text { do } \\
\text { tempo }\end{array}$ & $\begin{array}{c}\text { Expressões } \\
\text { textuais }\end{array}$ & $\begin{array}{c}\text { Marcador } \\
\text { do } \\
\text { início/final } \\
\text { da história }\end{array}$ & $\begin{array}{c}\text { Coerência } \\
\text { narrativa }\end{array}$ & $\begin{array}{c}\text { Partes } \\
\text { da } \\
\text { narração }\end{array}$ & $\begin{array}{c}\text { Fidelidade } \\
\text { ao texto } \\
\text { original }\end{array}$ \\
\hline A1 & $\mathbf{X}$ & & $\mathbf{X}$ & & $\mathbf{X}$ & & \\
\hline A2 & & & & & & & \\
\hline A3 & & & $\mathbf{X}$ & & $\mathbf{X}$ & & \\
\hline A12 & $\mathbf{x}$ & & $\mathbf{X}$ & & $\mathbf{X}$ & & \\
\hline A15 & & & & & & \\
\hline
\end{tabular}

Fonte: Brito (2013).

Diante desses resultados, também constatamos que algumas crianças ainda não se apropriaram de elementos fundamentais para a reconstrução do texto, pois não foram fieis às fórmulas principais do texto original e, em muitos casos, não conseguiram ordenar a sequência da narrativa, nem mesmo na escrita. Atribuímos este fato ao pouco contato das crianças com o texto literário e com atividades semelhantes a essa que propomos.

$4^{\circ}$ Atividade - Construindo um sonho - Os objetivos foram estimular a leitura de imagens e desenvolver a oralidade e a escrita. Metodologia utilizada: Mostramos as imagens do livro Construindo um sonho, de Marcelo Xavier. Enquanto mostrávamos às imagens do livro às crianças, as incentivávamos para que elas narrassem à história do livro de forma coerente, interligando as imagens, e, em seguida, escrevia no quadro o que elas diziam, propiciando a escrita coletiva de um texto.

Durante a execução desta atividade percebemos mais uma vez que as crianças ainda não conseguem contar uma história de forma sequenciada com maior elaboração, como o uso de marcadores de tempo e conjunções. Mesmo 
sendo estimuladas a contar uma história elas só conseguiram formular uma frase para cada ilustração, como podemos ler no quadro que segue:

\section{Construção coletiva do texto}

O homem construindo uma casa.

O homem colocando as telhas.

O homem colocando as portas.

O homem pintando a casa.

O homem regando plantas, plantando as flores e fazendo a cerca.

A casa no ar.

Fonte: Brito (2013).

Durante a leitura das imagens algumas crianças não conseguiram compreender as ilustrações e fizeram uma interpretação equivocada do que estava exposto, neste momento houve algumas discussões entre as crianças, pois as que compreenderam questionavam as que não entenderam e em alguns momentos foi preciso intervir e mediar as descobertas.

$5^{\circ}$ Atividade - O cachorro o menino - Os objetivos específicos para esta atividade foram estimular a leitura, a criatividade e trabalhar a escrita. Metodologia utilizada: leitura do livro o cachorro o menino, de Simone Bibian (2006) e confecção de origamis de cachorros. Depois da leitura e dos origamis confeccionados, solicitamos que as crianças escrevessem um nome para seu cachorro. O momento em que as crianças foram nomear os origamis foi preocupante, pois as crianças escolheram nomes com maior dificuldade para o registro escrito. Além disso, a confecção de origamis levou muito tempo para ser concretizada, o que resultou num tempo limitado para executar as atividades de leitura com as crianças, sem tempo necessário para escrever junto com os alunos todos os nomes escolhidos por eles na lousa, ficando a atividade inconclusa.

No entanto, mesmo não concluindo toda atividade as crianças gostaram muito da história e ficaram muito felizes com os cachorros de origamis confeccionados por eles. A proposta lúdica permitiu e fortaleceu a interação entre texto e leitor, evidenciando como as crianças se identificam com as personagens e quais suas reações e emoções diante dos eventos narrativos que a literatura proporciona. 
$6^{\circ}$ Atividade - Inventa desventa - Os objetivos foram estimular a leitura, mostrar a Biblioteca Municipal e ajudar as crianças na compreensão de textos literários. Nesta atividade, a proposta foi levar as crianças para conhecer a Biblioteca Municipal. Na biblioteca as crianças manusearam diversos livros de diferentes autores, pois é extremamente importante que o livro seja tocado pela criança, folheado, de forma que tenha um contato mais íntimo com o objeto do seu interesse. A partir daí, ela começa uma história de leitura que leva ao gosto por livros.

Depois de algum tempo lemos para elas o livro Inventa desventa, de Marta Lagarta (2009). Após contar a história do livro, voltamos para escola e, ao chegar na sala de aula, foi solicitado que desenhassem o que mais gostaram da história e que inventassem algumas coisas bem diferentes usando toda sua criatividade. Apenas três crianças não desenharam coisas referentes à narrativa do livro, as demais fizeram ilustrações muito bonitas e criaram desenhos bem diferentes. Diante das ilustrações e dos desenhos criados pelas crianças, consideramos um avanço positivo, pois as crianças conseguiram compreender a essência do texto lido, e isto, atribuímos ao contato rotineiro que estas crianças passaram a ter com o texto literário.

$7^{\circ}$ Atividade - livre escolha - Nesta atividade tínhamos como objetivos desenvolver a expressão oral, trabalhar a leitura, motivar a família das crianças a participarem do processo de alfabetização a partir da leitura de livros de literatura. Metodologia: Colocamos na sala muitos livros de literatura infantil para que as crianças manuseassem e depois escolhessem para leitura. Os livros escolhidos foram Dentro da casa tem..., de Márcia Alevi e Marilena Saito; A margarida friorenta, de Fernanda L. de Almeida e a A barba do tio Alonso, de Emma King-Farlow. Após a leitura destes livros cada criança escolheu um livro para levar para casa e ser lido/contado pelos pais ou por ela mesma. Como sabemos, o contato constante da criança com materiais de leitura é fundamental, como afirma Peruzzo (2011, p. 98):

Ouvir muitas e muitas histórias é importante para se integrar num mundo de descobertas e de compreensão do mundo. Ouvindo histórias pode-se também sentir emoções importantes, como a raiva, a tristeza, a irritação, o bem-estar, o medo, a alegria, o pavor, a insegurança, a tranquilidade. Enfim, ouvir 
narrativas é uma provocação para mergulhar profundamente em sentimentos, memórias e imaginações.

Desta forma, entendemos que quando contamos histórias às crianças estamos trabalhando intensamente com a sua imaginação, e, consequentemente, estamos construindo as noções de linearidade e coerência narrativa como o início e os finais de histórias, as referências aos elementos fundamentais da narração como a fidelidade ao texto e a sequência de apresentação do tempo, espaço e personagens, além de estimularmos à compreensão e interpretação dos textos.

$8^{\circ}$ Atividade - Reconto das narrativas - Os objetivos foram desenvolver a oralidade e trabalhar a compreensão de texto. Metodologia utilizada: solicitamos que as crianças recontassem a história dos livros que levaram para casa, mas as crianças não conseguiram realizar a tarefa, possivelmente porque ninguém contou a história (porque não houve tempo) ou 'não lembro'. Sendo assim a atividade não pode ser concluída.

Nesse caso, entendemos que alguns pais, ainda não compreendem a importância do contato da criança com o texto literário, pois neste dia em que as crianças levaram os livros também levaram atividades para casa e estas foram realizadas, mas alguns não leram os livros, o que confirma que a leitura dos livros é algo que não possui tanta relevância no seio familiar. Em relação às crianças que ouviram as histórias em casa e não conseguiram recontar de forma coerente ou não se lembraram da narrativa, atribuímos este fato ainda ao pouco contato que elas possuem com textos literários.

$9^{\circ}$ Atividade - Trava-lingua Quebra-queixo Rema-rema remelexo - Os objetivos são mostrar os diferentes tipos de textos literários, estimular a leitura, trabalhar a compreensão do texto. Metodologia utilizada: a leitura do livro Trava-lingua Quebra-queixo Rema-rema remelexo, de Almir Correia (2010).

Ao propormos esta atividade entendemos que é fundamental para a criança manter o contato com diferentes tipos de textos literários, pois preparam para diversas formas de ler e interpretar. Estas interpretações, associada à imaginação da criança, se transformam em um momento único de 
criação e ampliação do conhecimento, em que a criança é capaz de expressar tudo o que sabe, sente e pensa através de desenhos criados por ela. A proposta inicial era ilustrar os poemas do livro e confeccionar um livro, mas o tempo que tínhamos não foi suficiente, por isso não foi possível ilustrar todos os poemas e confeccionar o livro. Não demos continuidade na aula seguinte, pois as crianças levaram seus desenhos para casa e não trouxeram, desta forma passamos para a $10^{\circ}$ atividade.

$10^{\circ}$ Atividade: Que bicho será que botou o ovo? - Os objetivos foram trabalhar a oralidade e desenvolver a escrita. Metodologia utilizada: leitura do livro Que bicho será que botou o ovo? de Angelo Machado. Durante a leitura questionamos às crianças sobre que bicho eles achavam que botou o ovo? Depois pedimos para que eles desenhassem o bicho que eles achavam que estava dentro do ovo. Após todas as crianças terem terminado o desenho, o restante da história foi contada, acabando com o mistério do livro. Em seguida, pedimos para que escrevessem o que achavam que aconteceu para que o ovo fosse deixado ali sozinho; eis o resultado:

Quadro 7 - Resultados da $10^{\circ}$ Atividade

\begin{tabular}{|l|l|l|}
\hline \multicolumn{2}{|c|}{ Resultado da Atividade } \\
\hline Aluno & Escrita dos alunos & Leitura da escrita do aluno \\
\hline A1 & Porqueelatenimuito ovo & Porque ela tem muito ovo. \\
\hline A2 & ffacarétehScina & Jacaré pegadinha. \\
\hline A6 & 1 q ammõ & Porque a mamãe não queria. \\
\hline A7 & Ovuetioue & O ovo é de quem? \\
\hline A9 & $\begin{array}{l}\text { Porque eu acho quia mamãe } \\
\text { gacaredeichou ovo porque ela Não } \\
\text { gosta dele } \\
\text { porQueelateimmuito ovo }\end{array}$ & $\begin{array}{l}\text { Porque eu acho que a mamãe } \\
\text { jacaré deixou o ovo porque ela } \\
\text { não gosta dele. }\end{array}$ \\
\hline A12 & Porque ela tem muito ovo. \\
\hline
\end{tabular}

Fonte: Brito (2013).

Nessa etapa, observamos que $71 \%$ das crianças compreenderam a narrativa do texto e já conseguiram formular hipóteses sobre o que aconteceu para que o jacaré fêmea deixasse o ovo sozinho. Assim, concluímos que estes resultados são satisfatórios, pois houve um avanço considerável no desenvolvimento cognitivo das crianças, comparada à avaliação diagnóstica acima referida. No que se refere ao desenvolvimento da escrita dos alunos vejamos os resultados: 
Quadro 8 - Análise da $10^{\circ}$ atividade

\begin{tabular}{|l|c|c|c|c|}
\hline \multicolumn{5}{|c|}{ Níveis de escrita } \\
\hline Alunos & Pré-Silábico & Silábico & Silábico/ Alfabético & Alfabético \\
\hline A1 & & & $\mathbf{X}$ & \\
\hline A2 & & $\mathbf{X}$ & $\mathbf{X}$ & \\
\hline A6 & $\mathbf{X}$ & & & \\
\hline A7 & & $\mathbf{X}$ & & $\mathbf{X}$ \\
\hline A9 & & & $\mathbf{X}$ & \\
\hline A12 & & & \multicolumn{3}{|}{} \\
\hline
\end{tabular}

Fonte: Brito (2013).

Ao observar os resultados da atividade escrita percebemos que o avanço das crianças foi ainda maior, tendo em vista a primeira avaliação de escrita que propomos (quadro 3). Apenas uma criança permanece no nível de escrita présilábico e isto pode ser atribuído a baixa frequência escolar desta criança, enquanto que encontramos outra criança já no nível de escrita alfabético. Observamos, ainda, que nove crianças estão no nível silábico/alfabético.

Portanto, diante dos resultados das atividades de leitura e escrita que propomos, observamos progressivamente o avanço das crianças e como a literatura infantil foi fundamental neste processo de aquisição de leitura e da escrita, no entanto, é importante ressaltar que este é um processo que deve ser contínuo e que apenas dez atividades são insuficientes para que uma criança seja alfabetizada e letrada. Por isso, acreditamos que as atividades de leitura devem ser diárias, pois se bem planejadas favorecem o desenvolvimento de estratégias de leitura que sirvam de apoio à compreensão dos sentidos de um texto.

Neste caso, nada melhor do que a leitura de obras literárias como parte da rotina da escola, afinal esse contato constante permite a formação de um leitor mais autônomo, familiarizado com a escrita e motivado ao prazer da aventura de descortinar novas histórias e conhecer novos autores.

\section{Ainda considerações conclusivas}

No período em que executávamos o projeto de leitura nos deparamos com situações que definiam claramente o método de ensino pelo qual as crianças estavam sendo introduzidas à alfabetização e as dificuldades encontradas por elas no processo de aquisição da leitura e da escrita, sendo assim, os nossos 
objetivos específicos neste projeto se propuseram a todo o momento a estimular o gosto da leitura, a aquisição da escrita, a facilitar o desenvolvimento cognitivo e a aprendizagem das crianças a partir da leitura de livros de literatura infantil.

No início do projeto as crianças apresentaram muitas dificuldades na realização das atividades que propomos e, infelizmente, com isso não conseguimos atingir todos os objetivos. No entanto, no decorrer das atividades que propúnhamos e do contato com texto literário, as crianças conseguiram avançar significativamente e se desenvolver intelectualmente, e isto, foi possivel constatar ao confrontarmos e observarmos os resultados da primeira e da última $\left(10^{\mathrm{a}}\right)$ atividades do projeto de leitura.

Neste sentido, podemos afirmar que alcançamos o objetivo geral do projeto, tendo como resultado a clara percepção de que o contato com o texto literário através do projeto de leitura foi importante no processo de construção e reconstrução do conhecimento das crianças, pois a literatura ampliou os seus conhecimentos prévios e deu subsídios para que elas se apropriassem dos mecanismos da leitura e da escrita.

Registrar os resultados das atividades no projeto de leitura, realizadas pelas crianças, sua maneira de pensar, suas interpretações, seu raciocínio lógico e seu desenvolvimento cognitivo constituiu uma oportunidade única de reflexão sobre o ato de ler e escrever e atribuir significados, ao uso da escrita e da leitura. Portanto, é necessário que a comunidade escolar compreenda que o texto literário é indispensável na constituição de um leitor crítico, sendo efetivado na rotina diária das escolas.

Enfim, entendemos que a literatura Infantil se apresenta como uma opção pedagógica e estética que amplia o processo de ensino e aprendizagem da criança, uma vez que é capaz de contribuir na constituição do leitor competente. Na alfabetização, a literatura infantil desempenha múltiplos papéis, dos quais podemos destacar a construção e reconstrução do conhecimento que acontece a partir das leituras dos textos literários. 


\section{REFERÊNCIAS}

ALEVI, Márcia. Dentro da casa tem... Il. Marilena Saito. São Paulo: Scipione, 2008.

ALMEIDA, Fernanda Lopes. A margarida friorenta. Il. Lila Figueiredo. São Paulo: Ática, 2006.

BARBOSA. Maria Carmem. Projetos pedagógicos na educação infantil. Porto Alegre: Artmed, 2008.

BIBIAN, Simone. O cachorro, o menino. Il. Mariana Massarani. São Paulo: Manati, 2006.

BORTONI, Stella Maris. Métodos de Alfabetização e consciência fonológica: o tratamento de regras de variação e mudança. SCRIPTA, Belo Horizonte, v. 9, n. 18 , p. 201-220, $1^{\circ}$ sem. 2006.

BRASIL. Ministério da Educação. Pró-letramento: Programa de Formação Continuada de Professores dos Anos/Séries Iniciais do Ensino Fundamental: alfabetização e linguagem. 2008. Disponivel em: <http://portal.mec.gov.br/cne/arquivos/pdf/ rceb02_98.pdf>. Acesso em: 12 mar.2016.

BRITO, Rosa Suzana Alves de. Literatura infantil no processo de aquisição da leitura e da escrita. 2013. 143 f. Monografia (Graduação em Pedagogia) - UFPB, Mamanguape (PB), 2013. Disponivel em: $<$ http:/ / www.ufpb.br/geef/contents / documentos/tcc-literatura-infantil-noprocesso-de-aquisicao-da-leitura-e-da-escrita-1.pdf $>$. Acesso em: 10 jul. 2017.

CAGLIARI, L. C. Alfabetização \& Linguística. São Paulo: Scipione, 1992.

CORREIA, Almir. Trava-lingua Quebra-queixo Rema-rema remelexo. Il. Cláudia Ramos. São Paulo: Cortez, 2010.

CURTO. Luís Maruny; MORILLO. Maribel M.; TEIXIDÓ. Manuel M. Escrever e ler: Materiais e recursos para a sala de aula. Porto Alegre: Artmed, 2000.

FERREIRO, Emília; TEBEROSKI, Ana. A psicogênese da lingua escrita. Porto Alegre: Artmed, 2011.

FURNARI, Eva. A bruxinha atrapalhada. São Paulo: Global, 1982.

GROSSI, E. P. Alfabetização em classes populares: didática do nível pré-silábico. São Paulo: SE/CENP, 1985.

JUNQUEIRA, Sônia. O peru de peruca. Il. Alcy. São Paulo: Ática, 2004.

KING-FARLOW, Emma. A barba do tio Alonso. Il. Anna L. Cantone. Tradução de Eduardo Brandão. São Paulo: Companhia das Letrinhas, 2008. 
LAGARTA, Marta. Inventa, desventa. Il. Guto Lins. São Paulo: FTD, 2009.

LAJOLO, Marisa. Do mundo da leitura para a leitura do mundo. 6. ed. São Paulo: Editora Ática, 2008.

LOIS, Lena. Teoria e prática da formação do leitor: Leitura e literatura na sala de aula. Porto alegre: Artmed, 2010.

MACHADO, Angelo. Que bicho será que botou o ovo? Il. Roger Melo. Rio de Janeiro: Nova Fronteira, 1996.

PAULINO, Graça; COSSON, Rildo. Letramento Literário: para viver a literatura dentro e fora da escola. In: ZILBERMAN, R.; RÖSING, T. M. K. Escola e leitura: velha crise, novas alternativas. São Paulo: Global, 2009. p. 61-79.

PERUZZO, Adriana. A importância da literatura infantil na formação de leitores. Cadernos do CNLF, Rio de Janeiro, v. 15, n. 5, p. 95-104, 2011.Disponivel em: <http://www.filologia.org.br/xv_cnlf/tomo_1/08.pdf >. Acesso em: 4 abr. 2016.

REGO, Lúcia Lins Browne. Literatura Infantil: Uma nova perspectiva da alfabetização na pré-escola. 2. ed. São Paulo: FTD, 1995.

SANTAMARIA; Viviane L.; LEITÃO, Patrícia B; ASSENCIO-FERREIRA, Vicente José. A consciência fonológica no processo de Alfabetização. Revista CEFAC, São Paulo, v.6, n.3, p.237-41, 2004.

SISTO, Celso. Chá das dez. Il. Duke. Belo Horizonte: Aletria, 2010.

SOARES, Magda. Alfabetização e Literatura. Revista educação: Guia da alfabetização. São Paulo: ed. Segmento, n.2, 2010.

VIEIRA, Raquel P. F. O processo de aquisição da escrita pela criança na escola. In: EDIPE - ENCONTRO ESTADUAL DE DIDÁTICA E PRÁTICA DE ENSINO, 4., 2011, Goiânia. Disponivel em: <http://www.ceped.ueg.br/anais/ivedipe/pdfs / lingua_portuguesa/co/335-731-1SM.pdf> . Acesso em: 14 set. 2016.

XAVIER, Marcelo. Construindo um sonho. Belo Horizonte: RHJ, 1997. 